\title{
INFLUÊNCIA DA GEOMETRIA DO FERRAMENTAL NAS PROPRIEDADES MECÂNICAS DE FIOS DE COBRE FABRICADAS PELO PROCESSO CONFORM*
}

\author{
Gustavo Tressia ${ }^{1}$ \\ Leandro de Almeida² \\ Victor Caso Moreira
}

\section{Resumo}

Neste trabalho foi avaliada a influência da geometria da câmara de acumulação e da relação de extrusão na fabricação de fios de cobre por meio do processo de conformação contínua, Conform. Dois tipos de produtos foram fabricados, sendo um retangular com menor área de seção transversal e outro redondo com maior área. Para a condição do material redondo, dois tipos de câmara de acumulação foram utilizados, sendo uma de maior dimensão, resultando em maior acumulo de material antes da conformação pela matriz de extrusão. Medições de temperatura foram realizadas na matriz de extrusão. No produto final foram realizados ensaios de limite de resistência à tração, escoamento e alongamento. Ao longo da câmara de acumulação e no produto final foi realizada analise microestrutural e de tamanho de grão. Os resultados mostraram que o aumento da relação de extrusão promoveu aumento da temperatura do conjunto e consecutivamente aumento do tamanho de grão do produto final. Ao longo da câmara de acumulação foi observada uma tendência de redução do tamanho de grão até o produto de saída.

Palavras-chave: Conform; Conformação Contínua; Cobre.

\section{INFLUENCE OF THE TOOL GEOMETRY IN THE MECHANICAL PROPERTIES OF COPPER WIRE MANUFACTURED BY THE CONFORM PROCESS}

\section{Abstract}

In this work, the influence of the geometry of the accumulation chamber and of the extrusion ratio in the manufacture of copper wires was evaluated through the continuous forming process, Conform. Two types of products were manufactured, a rectangular with smaller area of cross section and another round with larger area. For the condition of the round material, two types of accumulation chamber were used, one being of a larger size, resulting in a higher accumulation of material before conformation by the extrusion die. Temperature measurements were performed on the extrusion die. Tensile strength, yield and elongation tests were performed in the final product. Through the accumulation chamber and the final product, a microstructural and grain size analysis was performed. The results showed that the increase of the extrusion ratio promoted increase of the temperature of the set and consequently increase of the grain size of the final product. During the accumulation chamber a tendency of reduction of grain size was observed until the final product.

Keywords: Conform; Continuous Forming, Copper.

1 Engenheiro Mecânico, Mestre, Engenheiro de Processos, Engenharia de Processos, Paranapanema SA, Santo André, São Paulo, Brasil.

2 Engenheiro Metalurgista, Engenheiro de Processos, Engenharia de Processos, Paranapanema SA, Santo André, São Paulo, Brasil.

3 Engenheiro Metalurgista, Engenheiro de Desenvolvimento, Desenvolvimento técnico, Paranapanema SA, Santo André, São Paulo, Brasil. 


\section{INTRODUÇÃO}

O processo CONFORM (do inglês "Continuous Forming) de extrusão contínua foi desenvolvido inicialmente por Derak Green em 1971, sendo considerada uma importante técnica empregada para quebrar a estrutura bruta de fundição dos vergalhões obtidos por fundição contínua (DASHU 1994). Após a conformação da matéria prima o processo é capaz de garantir a homogeneidade microestrutural do material conformado associada a excelentes tolerâncias dimensionais e qualidade superficial.

O processo Conform é utilizado para fabricação de seções ocas e maciças de metais não ferrosos, utilizando como matéria prima vergalhões ou particulados. Dentre as vantagens do processo destaca-se o fato de não ter nenhuma limitação de comprimento do produto conformado, menor consumo de energia em comparação a extrusão convencional e alta automação (SONG 2004). Outra vantagem importante do processo é devido a possibilidade de fabricação de materiais com área maior ou menor do que a área da matéria prima de entrada (vergalhão), ou seja, pelo processo é possível aumento ou redução de área, enquanto no processo de extrusão convencional é possível apenas redução de área.

$\mathrm{Na}$ Figura 1 é apresentado o princípio de funcionamento do processo. Como principais componentes destaca-se a roda de extrusão com um sulco circunferencial, a sapada estacionaria sobrepondo-se a uma parte da superfície da roda, formando assim uma espécie de câmara de extrusão. Destaca-se também a câmara de acumulação localizada antes da matriz, para garantir que sempre exista material suficiente para o completo preenchimento da matriz.

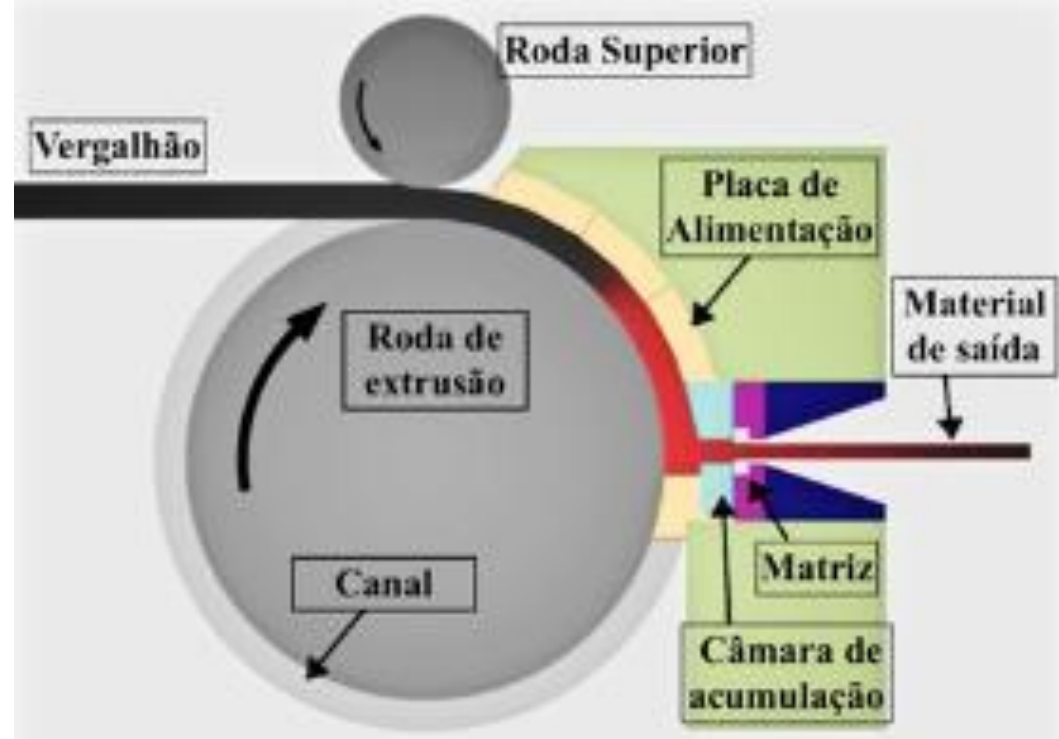

Figura 1. Diagrama de componentes do equipamento do processo Conform.

Na Figura 2 é apresentado em detalhe as alterações que o vergalhão é submetido ao longo da zona de expansão. Em uma região posterior ao contato inicial entre 0 vergalhão e a roda de extrusão existe a região de enchimento, sendo esta a região em que o vergalhão já deformado preenche todo o canal da roda de extrusão. Posteriormente encontra-se a região de recalque, onde o material deformado é removido do canal da roda e direcionado para a câmara de acumulação, em que o material é acumulado, expandindo assim a seção transversal, permitindo que exista material suficiente para o preenchimento completo da matriz de extrusão. 
O correto dimensionamento da câmara é importante pelo fato de estar relacionado a problemas de superaquecimento do conjunto, força excessiva de extrusão e falhas de preenchimento do produto. Porém, a variação do dimensional da câmara resulta em variações de temperatura do conjunto de ferramental, logo a variação da temperatura de extrusão do material fabricado, que por sua vez pode apresentar variações de propriedades mecânicas.

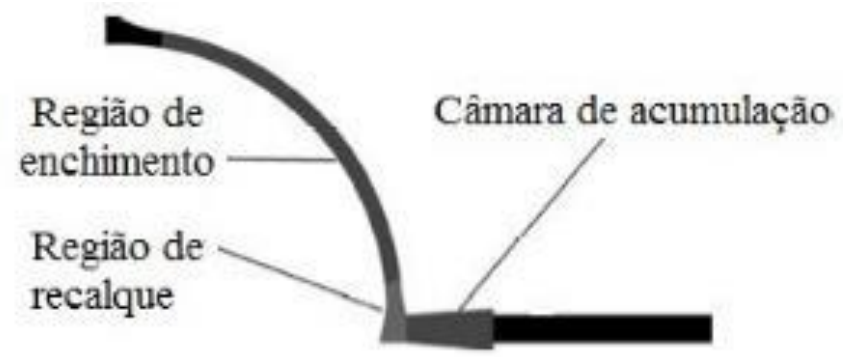

Figura 2. Zonas de expansão do processo Conform (Adpatado de Yun et al 2013).

No processo Conform, o aumento da relação de extrusão, ou seja, a redução da área da seção transversal do material produzido, tende a promover aumento de temperatura do conjunto e consecutivamente do material, para uma mesma velocidade e para o mesmo material de entrada. Segundo Huang e Logé (2016) durante o processo de recristalização dinâmica quanto maior a deformação e menor a temperatura do processo, menor será o tamanho de grão final do produto, e para maiores temperaturas ou menores deformações maior será o tamanho de grão.

A fim de verificar o comportamento da microestrutura no processo Conform, neste trabalho será avaliada a influência da deformação do material conformado, bem como o aumento de temperatura causado pelo aumento da deformação, por meio do processo de extrusão contínua, Conform. Como ocorre simultaneamente aumento de deformação e de temperatura, será avaliado qual destas alterações exercerá maior influência.

\section{MATERIAIS E MÉTODOS}

\subsection{Matéria prima}

Como matéria prima foi utilizado vergalhão fundido por meio do processo UPCAST, utilizando liga ASTM C10200, classificada de acordo com a norma ASTM B-187, conhecida como Cobre "Oxygen free", marcado pelo baixíssimo teor de oxigênio, podendo atingir um teor máximo de 10 ppm. O diâmetro médio do vergalhão utilizado foi de $12,50 \mathrm{~mm}$.

\subsection{Caracterização das amostras}

Para a preparação metalográfica as amostras foram polidas passando por lixa grana \#180 até \#1200, seguindo para polimento em pasta de diamante com grana de 9 a 1 $\mu \mathrm{m}$. Para a revelação da microestrutura as amostras foram imersas em trióxido de cromo durante 5 segundos. A análise da microestrutura foi realizada em microscópio óptico e as medições de tamanho de grão médio foram realizadas pelo método comparativo de imagens conforme proposto pela ASTM E112.

Para análise do material da câmara de acumulação, foi removido o material preservando seu formado e foi realizado um corte longitudinal, de modo a analisar a evolução da microestrutura ao longo de todo o processo de deformação, desde a 
saída do material da roda de extrusão até a entrada do material na matriz. Na Figura 3 são apresentadas as regiões que foram analisadas.

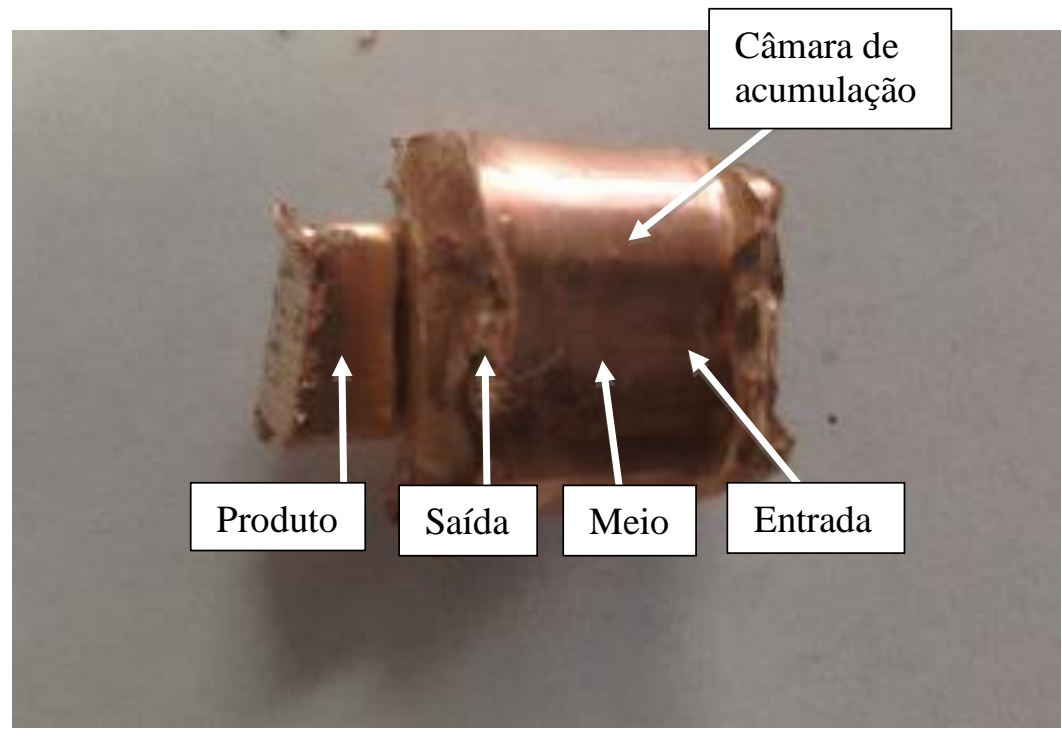

Figura 3. Material removido da câmara de acumulação com a regiões de análise.

Ensaios de limite de resistência a tração (LRT) e de escoamento (LE) foram realizados, com 5 repetições para cada condição.

\subsection{Fabricação}

Foram fabricadas duas geometrias de produtos de cobre pelo processo de extrusão contínua utilizando o equipamento TLJ300. Um dos materiais fabricados apresenta seção retangular com dimensional $15,36 \times 0,68 \mathrm{~mm}$, com área da seção transversal de $10,4 \mathrm{~mm}^{2}$ e relação de extrusão de 11,7 , e outro material com geometria circular com diâmetro de $9,52 \mathrm{~mm}$, área da seção transversal de $71,2 \mathrm{~mm}^{2}$ e relação de extrusão de 1,7. Para cada dimensional foram utilizadas duas câmaras distintas, ambas com geometria trapezoidal, porém com dimensional diferenciado,

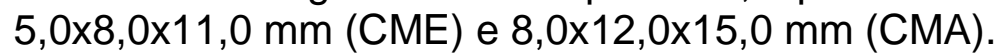

Quanto ao processo de fabricação, todos os materiais foram fabricados utilizando-se os mesmos parâmetros de processo, mantendo-se a velocidade de rotação da roda de extrusão constante a $6 \mathrm{rpm}$. Medições da temperatura da matriz de extrusão foram realizadas utilizando um termopar de contato.

\section{RESULTADOS E DISCUSSÃO}

Na Tabela 1 é apresentado a composição química da matéria-prima utilizada para a fabricação dos materiais analisados. Todos os materiais foram fabricados utilizandose o mesmo vergalhão fundido. 
Tabela 1. Composição química do vergalhão fundido

[\%]

\begin{tabular}{ccccccl}
\hline $\mathrm{Cu}$ & $\mathrm{O} 2$ & $\mathrm{Fe}$ & $\mathrm{Bi}$ & $\mathrm{Sn}$ & $\mathrm{Ni}$ & Classificação \\
\hline $\mathbf{9 9 , 9 9}$ & 0,0006 & 0,0001 & 0,0002 & 0,0001 & 0,0001 & UNS C10200 \\
\hline
\end{tabular}

$\mathrm{Na}$ Tabela 2 são apresentados os resultados dos ensaios de limite de resistência a tração e de escoamento.

Tabela 2. Limite de resistência a tração, limite de escoamento e tamanho de grão.

\begin{tabular}{ccccccc}
\hline Material & Formato & $\begin{array}{c}\text { Area } \\
{\left[\mathrm{mm}^{2}\right]}\end{array}$ & Câmara & $\begin{array}{c}\text { LRT } \\
{\left[\mathrm{kgf} / \mathrm{mm}^{2}\right]}\end{array}$ & $\begin{array}{c}\text { LE } \\
{\left[\mathrm{kgf} / \mathrm{mm}^{2}\right]}\end{array}$ & $\begin{array}{c}\text { Tamanho de } \\
\text { grão }[\mu \mathrm{m}]\end{array}$ \\
\hline $\mathbf{1}$ & Redondo & 71,2 & $\mathrm{CMA}$ & $24,13 \pm 0,11$ & $7,79 \pm 1,66$ & $18,1 \pm 0,8$ \\
\hline $\mathbf{2}$ & Redondo & 71,2 & $\mathrm{CME}$ & $24,33 \pm 0,14$ & $7,55 \pm 2,11$ & $19,6 \pm 1,5$ \\
\hline $\mathbf{3}$ & Retangular & 10,4 & $\mathrm{CME}$ & $23,02 \pm 0,02$ & $6,80 \pm 0,30$ & $29,7 \pm 5,1$ \\
\hline
\end{tabular}

Nota-se que, para uma mesma geometria de material, com aumento de acumulo de material na câmara de acumulação não foi observada variação significativa das propriedades mecânicas nem do tamanho de grão do produto final. Por outro lado, considerando para um mesmo dimensional da câmara de acumulação, menores valores de LRT e LE e maior valor de tamanho de grão foram encontrados para o material de menor área da seção transversal em comparação ao material com maior área.

$\mathrm{Na}$ Tabela 3 são apresentados os resultados obtidos das medições de temperatura matriz de extrusão e da amperagem do motor após a estabilização do processo. Para estabilização do processo foi estabelecida a produção de 20 metros do produto, garantindo assim que a amperagem e a temperatura não variassem ao longo dos testes.

Observa-se uma variação, aproximadamente, de temperatura de $100{ }^{\circ} \mathrm{C}$ e de corrente de $37 \mathrm{~A}$ apenas para o material retangular que apresenta menor área da seção transversal.

Considerando que o aumento de temperatura da matriz de extrusão é transmitido também para o produto, justifica-se o resultado apresentado na Tabela 2, de que o material com menor área de seção transversal (Material 3 - Retangular) apresentou maior tamanho de grão e menor valor de limite de resistência a tração, assim como mostrado por Huang e Logé (2016), em que no processo de recristalização dinâmica o tamanho de grão final é dependente da temperatura e da deformação. Neste caso, a variação da temperatura foi preponderante. 
Tabela 3. Temperatura da matriz e amperagem do equipamento.

\begin{tabular}{lllll}
\hline Amostra & Formato & Câmara & Temperatura [ $\left.{ }^{\circ} \mathbf{C}\right]$ & Corrente [A] \\
\hline $\mathbf{1}$ & Redondo & CMA & $513 \pm 5$ & $120 \pm 2$ \\
\hline $\mathbf{2}$ & Redondo & CME & $518 \pm 6$ & $118 \pm 2$ \\
\hline
\end{tabular}

$\mathrm{Na}$ Figura 4 são apresentadas as micrografias dos materiais, notando-se similaridade entre os tamanhos de grão, com exceção do Material 3 (Retangular). $\mathrm{Na}$ Figura 5, Figura 6 e Figura 7 é apresentado a evolução microestrutural do material localizado na câmara de acumulação em diferentes posições para os três materiais. Para todas condições nota-se uma microestrutura característica de ligas de cobre, marcado pela presença de apenas fase alfa.
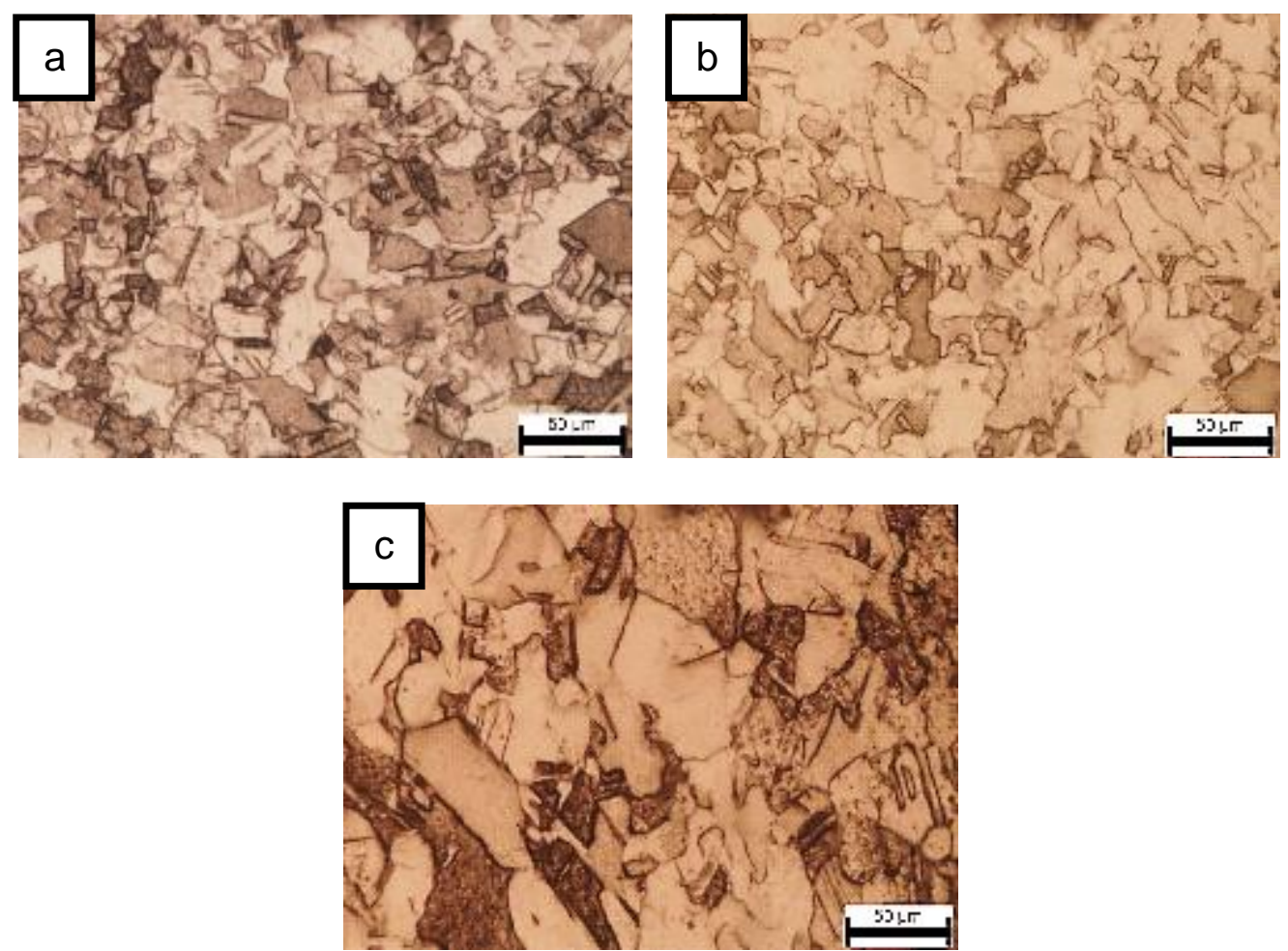

Figura 4. Microestrutura dos materiais: (a) 1 - Redondo (b) 2 - Redondo, (c) 3 - Retangular.

Assim como mostrado na Tabela 2, o tamanho de grão do material de menor área, Material 3 (retangular), apresentou maior valor, sendo possível notar pelas micrografias apresentadas na Figura 4. Isso mostra que a elevação da temperatura em aproximadamente $100^{\circ} \mathrm{C}$ exerceu maior influência nas propriedades do produto final do que o aumento da relação de extrusão, ou da deformação, em aproximadamente 7 vezes, variando de 1,7 (Material 2) para 11,7 (Material 3). 

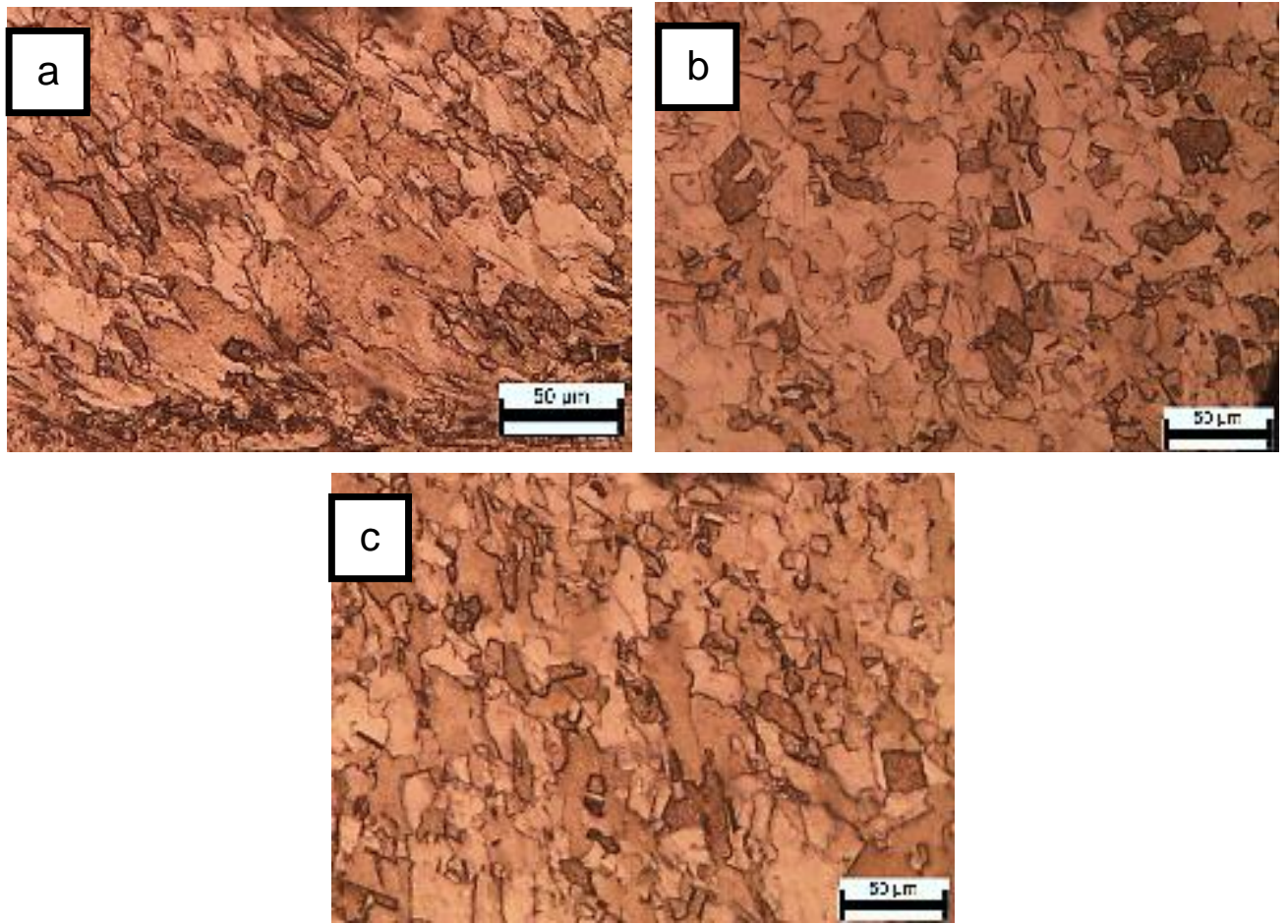

Figura 5. Evolução microestrutural do material localizado na câmara de acumulação para o Material 1 (Redondo), sendo (a) entrada da câmara de acumulação, (b) centro da câmara e (c) saída da câmara (entrada da matriz).
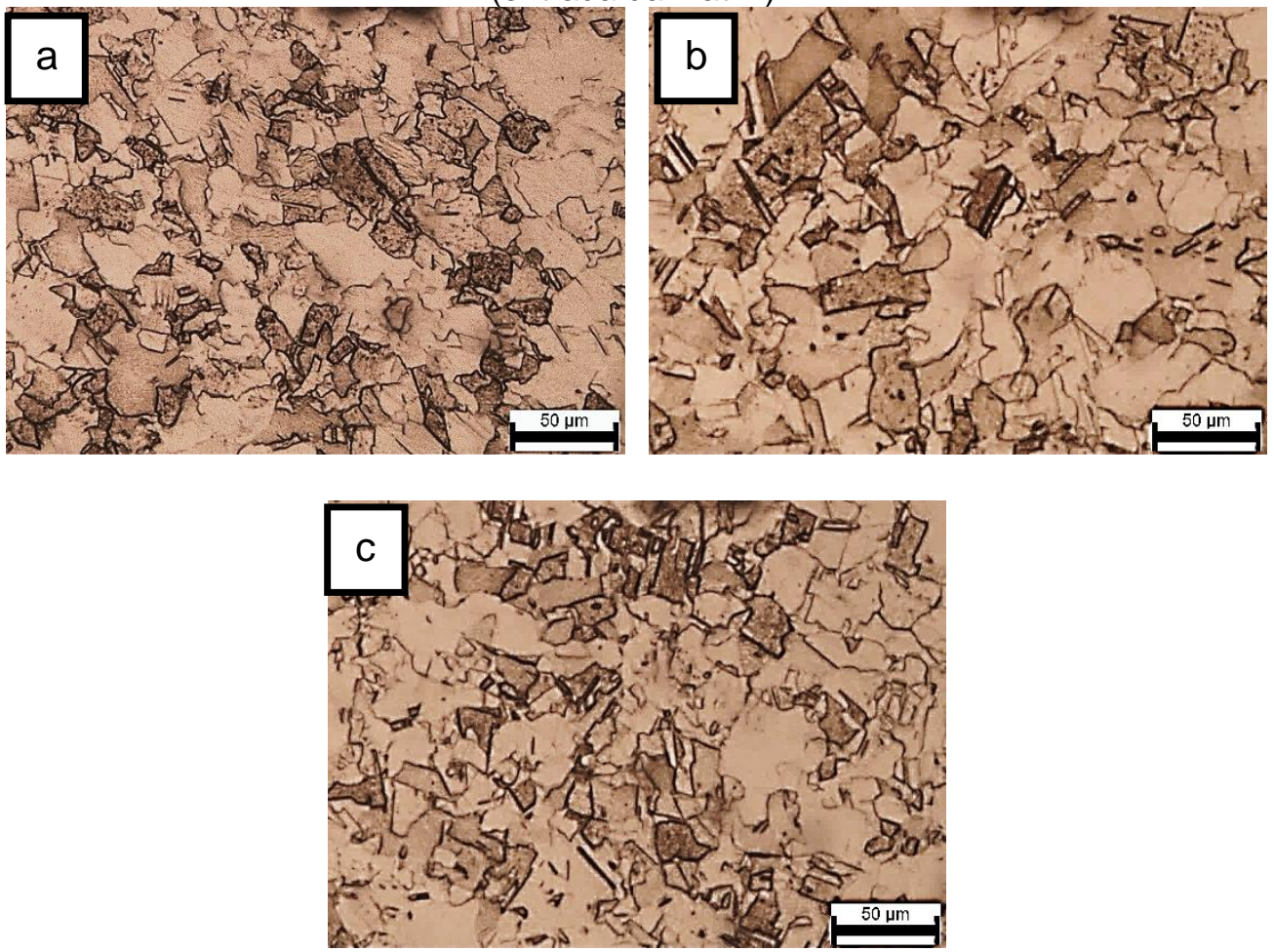

Figura 6. Evolução microestrutural do material localizado na câmara de acumulação para o Material 2 (Redondo), sendo (a) entrada da câmara de acumulação, (b) centro da câmara e (c) saída da câmara (entrada da matriz). 

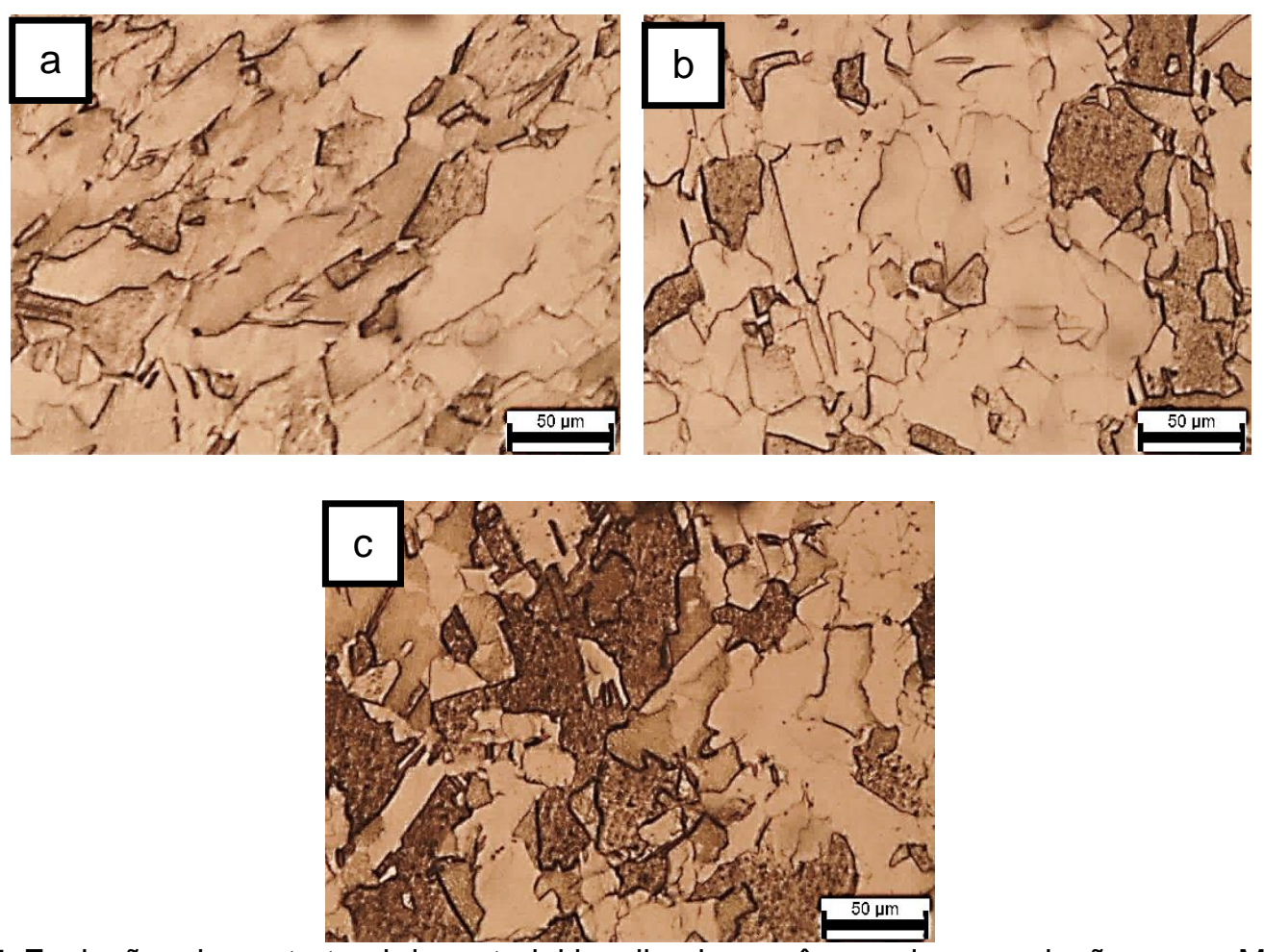

Figura 7. Evolução microestrutural do material localizado na câmara de acumulação para o Material 3 (Retangular), sendo (a) entrada da câmara de acumulação, (b) centro da câmara e (c) saída da câmara (entrada da matriz)

Na Figura 8 são apresentados os resultados de tamanho de grão ao longo da câmara até o produto de saída. Os materiais redondos, produzidos com câmaras diferentes apresentaram comportamento similares, sendo que em ambos os casos foi observada uma tendência de redução do tamanho de grão ao longo da câmara de acumulação até a saída do produto. Já o Material 3 (retangular) apresentou tamanho de grão superior aos demais materiais em todas posições da câmara de acumulação, apresentando uma queda acentuada do tamanho de grão ao longo da câmara. Porém, a evolução microestrutural foi a mesma para todos materiais, sendo marcada por uma região inicial de grão maiores ocorrendo uma tendência de redução do tamanho de grão ao longo da câmara, até a saída do material. Porém, não foi verificada diferença microestrutural entre a região de saída e o produto, após a matriz de extrusão.

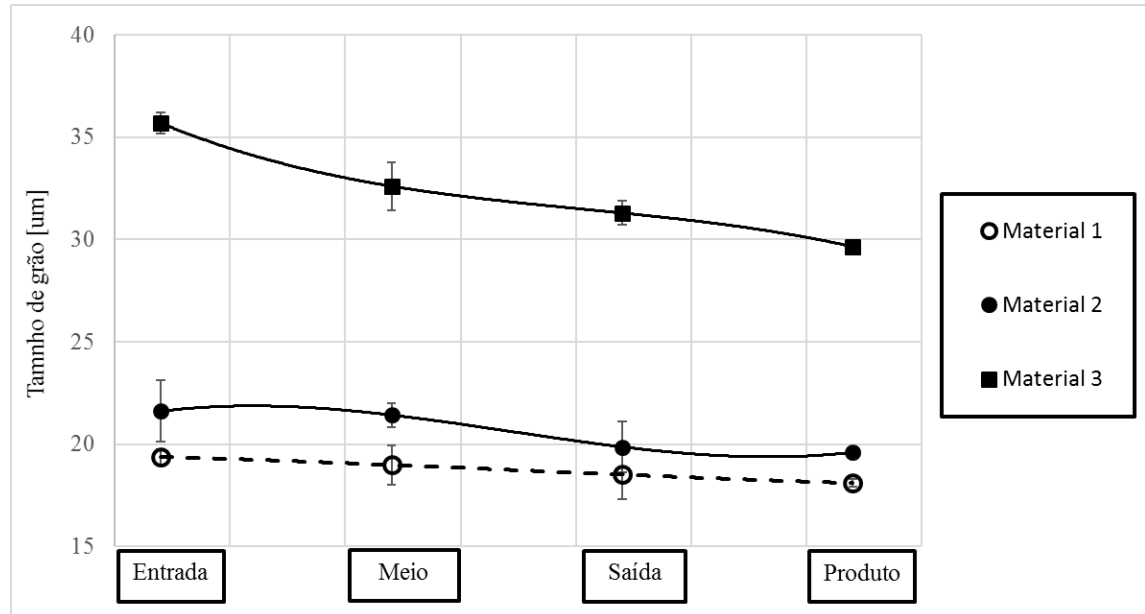

Figura 8. Medições de tamanho de grão ao longo da câmara de acumulação e do produto de saída. 


\section{CONCLUSÃO}

Para as condições avaliadas neste trabalho, conclui-se que a redução de área de $91,5 \%$ realizada durante a fabricação do fio de seção retangular com dimensões de $15,36 \times 0,68 \mathrm{~m}$ e relação de extrusão de 1,7 , promoveu aumento de temperatura durante o processo de conformação de aproximadamente $100^{\circ} \mathrm{C}$ em comparação aos produtos com redução de área de $42 \%$, de seção circular com diâmetro de 9,52 $\mathrm{mm}$ e relação de extrusão de 11,7 , obtendo assim um aumento do tamanho de grão final e detectando uma redução do limite de resistência à tração. Esse resultado demonstra que $o$ aumento de temperatura de 1,2 vezes foi preponderante perante 0 aumento da deformação de 6,9 vezes quanto ao tamanho de grão e as propriedades mecânicas.

A evolução microestrutural do material ao longo da câmara de acumulação até o produto final mostrou uma tendência de redução do tamanho de grão, sendo que, o tamanho de grão do produto final apresentou menor valor quando comparado com a região inicial da câmara. Para o produto com maior relação de extrusão esse efeito foi mais pronunciado. Para um mesmo produto de seção circular, a variação da geometria da câmara de acumulação não exerceu influência significativa quanto as propriedades mecânicas e o tamanho de grão do produto fabricado.

\section{Agradecimentos}

Os autores agradecem a Paranapanema SA pelo incentivo a pesquisa.

\section{REFERÊNCIAS}

1 DASHU P. Pressure distribution on the grip zones in the conform process. Journal of Central South University of Technology Vol. 1, 1994. p. 35-39.

2 SONG L., ZHIMIN, Y. Y. Microstructural Evolution in Cu-Mg Alloy Processed by Conform. International Journal of Nonferrous Metallurgy, 2013, 2: 100- 105.

3 WOOD PKC. The mechanics of the Conform Continuous Extrusion Process. Doctorate thesi. University oh Aston in Birmingham. 1990. P. 336.

4 HUANG, K., LOGÉ, R.E. A review on dynamic recrystallization phenomena in metallic materials. Material Design, 2016. 